\title{
NON-COGNITIVE ABILITIES AND LABOR MARKET OUTCOMES: THE ROLE OF WORK ETHIC AND PERSONALITY TRAITS ON SUPERVISORY STATUS AND PROMOTION
}

\author{
Yu-Wei Luke Chu \\ School of Economics and Finance \\ Victoria University of Wellington \\ Susan J. Linz \\ Department of Economics \\ Michigan State University
}

\begin{abstract}
A growing literature suggests that noncognitive abilities are important determinants of earnings. But empirical research on nonwage labor market outcomes is still limited due to data availability. In this paper, we collect employer-employee linked data from six former socialist countries and estimate three noncognitive abilities: adherence to work ethic, the preference for challenge versus affiliation, and locus of control, and their relationship with workers' supervisory status and promotions. We find that these noncognitive abilities are strong predictors of the likelihood of being a supervisor and being promoted as well as the number of supervisees and promotions. We also study the role of noncognitive abilities in the gender gap in these labor market outcomes. Based on a Blinder-Oaxaca decomposition, gender differences in these noncognitive abilities can explain a modest proportion of the gender gap in supervisory status and promotions.
\end{abstract}

\section{Introduction}

Common sense suggests that both cognitive and noncognitive abilities play an important role in shaping labor market outcomes. It is intuitive that a person's attitude and personality should affect his/her wages or promotions, and many surveys show that employers value attitude towards work or communication skills more than years of schooling, industry-based credentials, or technical skills (Bowles, Gintis, \& Osborne, 2001). There is indeed ample evidence from psychology showing that, while cognitive ability is a powerful predictor of economic and social outcomes, noncognitive ability is equally important. However, most of the literature in labor economics focus mainly on traditional human capital predictors such as education, experience or job training programs. It is until very recently that economists begin to apply many measurements of cognitive and noncognitive abilities developed by psychologists (Borghans, Duckworth, Heckman, \& Weel, 2008). There has been many studies on general cognitive ability, or I.Q., measured by standardized achievement or general aptitudes tests such as the Armed Forces Qualification Test (AFQT) in the U.S. [For a summary of evidence see Cawley, Heckman, and Vytlacil (2001).] On the other hand, the literature on noncognitive abilities such as work ethic and personality is growing but it is still relatively small.

The relationship between noncognitive abilities and labor market outcomes has been addressed only by a few studies from European countries and mainly by studies from the U.S. It is not clear 
whether these results can be applied directly to less developed economies since some of the returns to noncognitive abilities might be culturally or institutionally specific. In addition, almost all of the existing studies focus on wages, and there is very little research examining other aspects of labor market outcomes due to lack of data. In this paper, we collect a large linked employer-employee data with detail information from six former socialist countries (Armenia, Azerbaijan, Kazakhstan, Kyrgyzstan, Russia, and Serbia) and study the relationship between noncognitive abilities and supervisory status and promotions in workplaces. Although we do not have a representative sample, the detailed information in our data allow us to examine labor market outcomes that are not well studied by previous research. Becoming a supervisor or being promoted represent an important change in a worker's career. It is not only associated with an individual's movement up the firm hierarchy but assuming significant types of responsibilities and decision-making authority (Kosteas, 2011; Rothstein, 2001). Studying vertical mobility within firms help economists to build a more complete picture of the role of noncognitive abilities in labor market outcomes.

We construct three different measures of noncognitive abilities from our detailed survey data: preference for challenge versus affiliation (C-A), locus of control (LOC), and adherence to the Protestant work ethic (PWE). We estimate linear probability models to study these noncognitive abilities and their effects on the likelihood of holding a supervisory position or receiving promotions. We also estimate the effects of noncognitive abilities on the number of supervisees or promotions because the intensive margin is as important as the extensive margin and approximately represents the level of a worker's position within a firm. The linked employer-employee data permit us to include firm fixed effects in the models to better account for potential firm heterogeneity. To preview our results, we find that preference for challenge, internal locus of control, and stronger adherence to work ethic are all positively associated with supervisory status and promotions. Specifically, one standard deviation increase in C-A, LOC, and PWE leads to an increase in the likelihood of being a supervisor of 2.5, 2.1, and 3.4 percentage points, respectively. We also find that one standard deviation increase in C-A and PWE leads to an increase in the likelihood of receiving promotions by 3.0 and 1.6 percentage points, but LOC does not appear to be a strong predictor of promotion. In terms of percentage changes, these estimates indicate about a $5-10 \%$ increase in the probability of being a supervisor or being promoted. For the intensive margin, a worker scored one standard deviation higher in C-A, LOC, and PWE supervises 0.4 (9\%), 0.7 (16\%), and 0.8 (17\%) more employees. Also, a worker scored one standard deviation higher in C-A and PWE receives 0.07 $(8 \%)$ and $0.06(6 \%)$ more promotions, but LOC is not a significant predictor for the number of promotions. The estimate magnitudes for these noncognitive abilities are about one third to two third of the estimates for education and self-report performance that are closely related to cognitive abilities.

Another focus of this paper is to link gender differences in noncognitive abilities to the observed gender gap in supervisory status and promotions. Numerous psychological studies have shown that noncognitive abilities like work ethic and personality traits tend to vary by gender (Costa Jr, Terracciano, \& McCrae, 2001; Meriac, Poling, \& Woehr, 2009; Schmitt, Realo, Voracek, \& Allik, 2008). However, very little empirical research in economics explores the implication of gender differences in noncognitive abilities in labor market outcomes. In this paper, we document that there exist moderate mean-differences in these noncognitive abilities across gender of $5-18 \%$ of one standard deviation. We also perform a Blinder-Oaxaca decomposition to decompose the 
gender gap in supervisory status or promotions into the gender differences in means and in coefficients. The results indicate that mean-differences in noncognitive abilities comprise most of the explained gender differences and they can explain a modest proportion of the total gender gap in these labor market outcomes. The gender mean-differences in these noncognitive abilities account for around $8 \%$ of the total gender gap in supervisory status and $13-18 \%$ of the total gender gap in promotions.

\section{Data Description}

Under the auspices of a project designed to investigate factors influencing worker performance in formerly socialist economies, an employee survey was conducted in Russia, Armenia, Azerbaijan, Kazakhstan, Kyrgyzstan and Serbia. Local project coordinators contacted over 700 workplaces to request permission to conduct the survey. In organizations where permission was granted, the questionnaire was administered in common areas or at specific job sites in the workplace. If workers agreed to participate, they had the option of returning a complete or incomplete questionnaire. More than 10,880 employees in over 665 workplaces participated. While cost constraints precluded generating a representative sample in any of the countries, our convenience samples represent a wide variety of workers and workplaces, and involve multiple geographic locations in each country. For the purposes of this paper, we restrict the country samples to include only those participants who answered all questions relevant to this analysis of noncognitive abilities and worker characteristics, giving us a total of 7,502 observations for promotions and 7,460 observations for supervisory status.

The descriptive statistics for worker characteristics and noncognitive abilities are in Table 1 . In our sample, $57 \%$ of the workers are females and about half of female workers are married. The average schooling of workers is 14.6 years. The relatively high level of education among participants is likely caused by the nature of the survey project - the level of reading required to complete the questionnaire and the individual's willingness to participate in a "research project." There are four composite measures for self-report performance and three noncognitive abilities, preference for challenge versus affiliation (C-A), locus of control (LOC), and adherence to the Protestant work ethic (PWE). All of these composite measures are summed from a series of questions and rescaled to be between 0 and 1 . Workers who scored higher in C-A, LOC, and PWE prefer challenge over affiliation in a working environment, exhibit internal locus of control, and more adhere to work ethic. One third of workers classify themselves as holding a supervisory position and nearly half of workers have received promotions from their current workplaces, regardless of gender. On average, workers supervise 4.47 people and receive 0.48 promotions.

Table 1 also presents the mean-differences for worker characteristics and noncognitive abilities across gender. Male workers are 8.6 percentage points more likely to hold a supervisory position and supervise $2.1(2.07 / 4.47=47 \%)$ more employees than female workers. The gender gap in holding a supervisory position is actually very close to that in in the U.S. which is about 69 percentage points difference (Rothstein, 2001). On average, although the likelihood of receiving at least one promotion for males is not significantly different from females, male workers receive $0.06(0.06 / 0.90=7 \%)$ more promotions than female workers. Table 1 suggests that female workers, on average, appear to have less favorable noncognitive abilities than male workers. Females have preference for affiliation over challenge, are more likely to exhibit an external LOC, 


\begin{tabular}{|c|c|c|c|c|}
\hline & Pooled & Male & Female & $\begin{array}{l}\text { Gender } \\
\text { Difference }\end{array}$ \\
\hline Women & $\begin{array}{c}0.57 \\
(0.49)\end{array}$ & & & \\
\hline Married Woman & $\begin{array}{c}0.29 \\
(0.45)\end{array}$ & & & \\
\hline Married & $\begin{array}{c}0.54 \\
(0.50)\end{array}$ & $\begin{array}{c}0.59 \\
(0.49)\end{array}$ & $\begin{array}{c}0.51 \\
(0.50)\end{array}$ & $\begin{array}{l}0.078^{* * *} \\
(0.012)\end{array}$ \\
\hline Years of Schooling & $\begin{array}{l}14.56 \\
(2.75)\end{array}$ & $\begin{array}{l}14.53 \\
(2.74)\end{array}$ & $\begin{array}{l}14.58 \\
(2.76)\end{array}$ & $\begin{array}{l}-0.042 \\
(0.064)\end{array}$ \\
\hline Age (at time of interview) & $\begin{array}{c}36.65 \\
(11.07)\end{array}$ & $\begin{array}{c}36.39 \\
(10.85)\end{array}$ & $\begin{array}{c}36.85 \\
(11.11)\end{array}$ & $\begin{array}{l}-0.451^{*} \\
(0.257)\end{array}$ \\
\hline Job Tenure (years at current workplace) & $\begin{array}{c}7.23 \\
(7.71)\end{array}$ & $\begin{array}{c}6.23 \\
(6.56)\end{array}$ & $\begin{array}{c}7.97 \\
(8.37)\end{array}$ & $\begin{array}{l}-1.744^{* * *} \\
(0.179)\end{array}$ \\
\hline Unemployment Exp.(in the past 5 yrs.) & $\begin{array}{c}0.34 \\
(0.47)\end{array}$ & $\begin{array}{c}0.34 \\
(0.47)\end{array}$ & $\begin{array}{c}0.34 \\
(0.47)\end{array}$ & $\begin{array}{l}-0.003 \\
(0.011)\end{array}$ \\
\hline Holding Multi-jobs & $\begin{array}{c}0.12 \\
(0.33)\end{array}$ & $\begin{array}{c}0.15 \\
(0.36)\end{array}$ & $\begin{array}{c}0.11 \\
(0.31)\end{array}$ & $\begin{array}{l}0.040^{* * *} \\
(0.008)\end{array}$ \\
\hline Performance & $\begin{array}{c}0.63 \\
(0.15)\end{array}$ & $\begin{array}{c}0.64 \\
(0.15)\end{array}$ & $\begin{array}{c}0.62 \\
(0.14)\end{array}$ & $\begin{array}{l}0.016^{* * *} \\
(0.003)\end{array}$ \\
\hline C-A & $\begin{array}{c}0.46 \\
(0.13)\end{array}$ & $\begin{array}{c}0.46 \\
(0.13)\end{array}$ & $\begin{array}{c}0.46 \\
(0.12)\end{array}$ & $\begin{array}{l}0.006^{* *} \\
(0.003)\end{array}$ \\
\hline Locus of Control & $\begin{array}{c}0.53 \\
(0.13)\end{array}$ & $\begin{array}{c}0.54 \\
(0.12)\end{array}$ & $\begin{array}{c}0.52 \\
(0.13)\end{array}$ & $\begin{array}{l}0.015^{* * *} \\
(0.003)\end{array}$ \\
\hline Work Ethic & $\begin{array}{c}0.50 \\
(0.12)\end{array}$ & $\begin{array}{c}0.51 \\
(0.11)\end{array}$ & $\begin{array}{c}0.49 \\
(0.11)\end{array}$ & $\begin{array}{l}0.021^{* * *} \\
(0.003)\end{array}$ \\
\hline Being a Supervisor & $\begin{array}{c}0.33 \\
(0.47)\end{array}$ & $\begin{array}{c}0.38 \\
(0.49)\end{array}$ & $\begin{array}{c}0.30 \\
(0.46)\end{array}$ & $\begin{array}{l}0.086^{* * *} \\
(0.011)\end{array}$ \\
\hline Number of People Supervised & $\begin{array}{c}4.47 \\
(16.54)\end{array}$ & $\begin{array}{c}5.65 \\
(18.42)\end{array}$ & $\begin{array}{c}3.58 \\
(14.91)\end{array}$ & $\begin{array}{l}2.072^{* * *} \\
(0.386)\end{array}$ \\
\hline Ever Receiving Promotions & $\begin{array}{c}0.48 \\
(0.50)\end{array}$ & $\begin{array}{c}0.49 \\
(0.50)\end{array}$ & $\begin{array}{c}0.48 \\
(0.50)\end{array}$ & $\begin{array}{l}0.010 \\
(0.012)\end{array}$ \\
\hline Number of Promotions Received & $\begin{array}{c}0.91 \\
(1.27)\end{array}$ & $\begin{array}{c}0.94 \\
(1.37)\end{array}$ & $\begin{array}{c}0.87 \\
(1.20)\end{array}$ & $\begin{array}{l}0.063^{* *} \\
(0.030)\end{array}$ \\
\hline
\end{tabular}

and less adhere to work ethic. For the composite performance measure, females also report worse self-assessed performance than males. The mean-differences in these composite measures are all statistically significant, measured in standard deviations, the gender differences are of $5-18 \%$ of one standard deviation.

\section{Empirical Model}

To study the determinants of labor market outcomes, we estimate linear models by OLS as follows:

(1) $Y_{i}=$ noncognitive abilities $+X_{i} \gamma+$ firm characteristics $/$ fixed effects $+\varepsilon_{i}$

where $Y_{i}$ is one of the four outcome variables: a dummy variable of being a supervisor, the number of people supervised, a dummy of ever receiving promotions in the current firm, and the number of promotion received in the current firm. The variables of main interests are the 
three composite measures for non-cognitive abilities: preference for challenge versus affiliation (C-A), locus of control (LOC), and adherence to the Protestant work ethic (PWE). $X_{i}$ is a vector of worker characteristics from Table 1, including gender, marital status, a dummy for being a married woman, years of schooling, age and its square, workplace tenure and its square, a dummy indicating unemployment experience in the past five years, a dummy for holding multiple jobs, and the composite measure of self-reported performance. To study whether or not the relationships between the above noncognitive abilities and supervisory status and promotions differ across gender, we also estimate Equation (1) separately for males and females. In the basic specification, we control for a number of firm characteristics: a dummy variable equals one if state-owned organization, sector dummy variables (construction/transportation, education/health, finance, manufacturing, retail and other services, and public sector as the omitted sector), and dummy variables for each country (Russia as the omitted country). However, firm heterogeneity may bias the estimates in our cross-sectional regressions. For instance, if firms that attract workers with higher noncognitive abilities have more opportunities for promotions, there will be an upward bias in the estimates for these noncognitive abilities. In the extended specification, because we have employeremployee linked data, we nonparametrically control for workplace heterogeneity by including firm fixed effects (dummies for each firm) in the models. Throughout of this paper, the estimated standard errors are clustered at firm level and therefore are robust to any withinfirm correlation and heteroskedasticity.

\section{Regression Result}

Table 2 presents the estimates from regressions of holding a supervisory position and the number of supervisees. To illustrate the changes in results, we show both the estimates from models with and without the inclusion of non-cognitive abilities, C-A, LOC, and PWE. We control for firm characteristics in Columns (1) - (2) and (5) - (6) and control for firm fixed effects in Columns (3) - (4) and (7) - (8). In the left panel, Columns (1) through (4), the dependent variable is a dummy variable for being a supervisor. In the left panel, to make interpretation easier, we scale the estimates and estimated standard errors by 100 and thus they reflect differences in percentage points. In the right panel, Columns (5) through (8), the dependent variable is the number of people supervised that can be viewed as a proxy for the level of a worker's position and supervisory responsibilities (especially when controlling for firm fixed effects and thus firm sizes).

First we note that, in both panels, most of the estimates from the specification with firm characteristics are quantitatively similar to the estimates from the specification with firm fixed effects. It seems that firm heterogeneity does not play an important role in the current context. Second, in both panels, most of the estimates for worker characteristics are quantitatively similar when these three measures of noncognitive abilities are included, suggesting that $\mathrm{C}-\mathrm{A}$, LOC, and PWE are not strongly correlated with other explanatory variables in determining supervisory status. If our composite measures of noncognitive abilities were strongly correlated with other explanatory variables in the models, especially with education or self-report performance that are closely related with cognitive abilities, we would be concerned that they may just capture the effects of other aspects of cognitive abilities. However, the estimates for education and self-report performance only decrease a little bit. The fact that these measures of noncognitive abilities indeed explain additional variations that are not explained by other 
explanatory variables provides further support for our composite measures of C-A, LOC, and PWE to be valid measures of noncognitive abilities.

Table 2: Determinants of Supervisory Status

\begin{tabular}{|c|c|c|c|c|c|c|c|c|}
\hline & (1) & (2) & (3) & (4) & (5) & (6) & (7) & (8) \\
\hline & & Being a $\mathrm{S}$ & Supervisor & & Num & lber of Pec & ople Supe & rvised \\
\hline Womon & $-4.24 * * *$ & $-3.51 * *$ & $-4.80 * * *$ & $-3.90 * *$ & -0.91 & -0.69 & $-1.32^{* *}$ & $-1.11^{*}$ \\
\hline |voment & $(1.62)$ & $(1.61)$ & $(1.74)$ & $(1.71)$ & $(0.60)$ & $(0.57)$ & $(0.66)$ & $(0.65)$ \\
\hline Marrind Womn & $-8.37^{* * *}$ & $-8.50^{* * *}$ & $-9.68^{* * *}$ & $-9.85^{* * *}$ & $-2.78^{* * *}$ & $-2.79 * * *$ & $-2.85^{* * *}$ & $-2.87^{* * *}$ \\
\hline IVrartiea voman & $(2.31)$ & $(2.28)$ & $(2.37)$ & $(2.33)$ & $(0.75)$ & $(0.74)$ & $(0.75)$ & $(0.75)$ \\
\hline Morriod & $10.39 * * *$ & $10.26^{* * *}$ & * $11.71^{* * *}$ & $11.55^{* * *}$ & $1.73^{* * *}$ & $1.66^{* * *}$ & $1.64^{* *}$ & $1.57^{* *}$ \\
\hline |liartiea & $(1.79)$ & $(1.77)$ & $(1.79)$ & $(1.76)$ & $(0.64)$ & $(0.63)$ & $(0.67)$ & $(0.67)$ \\
\hline & $1.91^{* * *}$ & $1.78^{* * *}$ & $2.12^{* * *}$ & $1.95^{* * *}$ & $0.50^{* * *}$ & $0.47^{* * *}$ & $0.53^{* * *}$ & $0.48^{* * *}$ \\
\hline scriooning & ${ }^{g}(0.31)$ & $(0.30)$ & $(0.34)$ & $(0.33)$ & $(0.10)$ & $(0.10)$ & $(0.12)$ & $(0.11)$ \\
\hline Age & $1.77^{* * *}$ & $1.85^{* * *}$ & $1.60^{* * *}$ & $1.71^{* * *}$ & $0.41^{* * *}$ & $0.44^{* * *}$ & $0.42^{* * *}$ & $0.45^{* * *}$ \\
\hline Age & $(0.39)$ & $(0.38)$ & $(0.42)$ & $(0.41)$ & $(0.14)$ & $(0.14)$ & $(0.15)$ & $(0.15)$ \\
\hline Age Squared & $\begin{array}{l}-0.01^{* * *} \\
(0.00)\end{array}$ & $\begin{array}{l}-0.02^{* * *} \\
(0.00)\end{array}$ & $\begin{array}{l}-0.01^{* *} \\
(0.01)\end{array}$ & $\begin{array}{l}-0.01^{* * *} \\
(0.01)\end{array}$ & $\begin{array}{l}-0.00^{* * *} \\
(0.00)\end{array}$ & $\begin{array}{l}-0.00^{* * *} \\
(0.00)\end{array}$ & $\begin{array}{l}-0.00^{* * *} \\
(0.00)\end{array}$ & $\begin{array}{l}-0.00^{* * *} \\
(0.00)\end{array}$ \\
\hline Ioh Tenure & $1.63^{* * *}$ & $1.68^{* * *}$ & $2.06^{* * *}$ & $2.12^{* * *}$ & $0.48^{* * *}$ & $0.49 * * *$ & $0.57^{* * *}$ & $0.59 * * *$ \\
\hline pod indure & $(0.35)$ & $(0.35)$ & $(0.34)$ & $(0.34)$ & $(0.11)$ & $(0.11)$ & $(0.13)$ & $(0.13)$ \\
\hline Job Tenure & $-0.04^{* * *}$ & $-0.04^{* * *}$ & $-0.05^{* * *}$ & $-0.05^{* * *}$ & $-0.01^{* *}$ & $-0.01^{* *}$ & $-0.01^{* *}$ & $-0.01^{* *}$ \\
\hline Squared & $(0.01)$ & $(0.01)$ & $(0.01)$ & $(0.01)$ & $(0.00)$ & $(0.00)$ & $(0.00)$ & $(0.00)$ \\
\hline Unemployment & -1.89 & -1.57 & $-4.49^{* * *}$ & $-4.35^{* * *}$ & 0.21 & 0.31 & -0.52 & -0.47 \\
\hline Unemproyment & $(1.44)$ & $(1.43)$ & $(1.47)$ & $(1.45)$ & $(0.38)$ & $(0.37)$ & $(0.42)$ & $(0.42)$ \\
\hline Holding Multi- & $4.23^{* *}$ & $4.04^{* *}$ & $3.76^{* *}$ & $3.52^{*}$ & 0.69 & 0.64 & 0.87 & 0.81 \\
\hline jobs & (1.89) & $(1.89)$ & $(1.85)$ & $(1.82)$ & $(0.79)$ & $(0.78)$ & $(0.87)$ & $(0.86)$ \\
\hline Performance & $\begin{array}{l}51.08^{* * *} \\
(4.45)\end{array}$ & $\begin{array}{l}47.75^{* * *} \\
(4.44)\end{array}$ & $\begin{array}{l}\text { * } 49.73^{* * *} \\
(4.52)\end{array}$ & $\begin{array}{l}45.50^{* * *} \\
(4.41)\end{array}$ & $\begin{array}{l}9.13^{* * *} \\
(1.37)\end{array}$ & $\begin{array}{l}8.26^{* * *} \\
(1.38)\end{array}$ & $\begin{array}{l}9.40^{* * *} \\
(1.53)\end{array}$ & $\begin{array}{l}8.42^{* * *} \\
(1.55)\end{array}$ \\
\hline C-A & & $\begin{array}{l}15.18^{* * *} \\
(4.98)\end{array}$ & & $\begin{array}{l}19.09^{* * * *} \\
(4.59)\end{array}$ & & $\begin{array}{l}1.83 \\
(1.54)\end{array}$ & & $\begin{array}{l}2.74^{*} \\
(1.59)\end{array}$ \\
\hline Locus of Control & & $\begin{array}{l}11.78^{* *} \\
(5.04)\end{array}$ & & $\begin{array}{l}16.48^{* * *} \\
(4.80)\end{array}$ & & $\begin{array}{l}3.65^{*} \\
(1.92)\end{array}$ & & $\begin{array}{l}5.41^{* *} \\
(2.13)\end{array}$ \\
\hline Work Ethic & & $\begin{array}{l}19.96^{* * *} \\
(5.29)\end{array}$ & & $\begin{array}{l}28.06^{* * *} \\
(5.38)\end{array}$ & & $\begin{array}{l}7.90^{* * *} \\
(2.19)\end{array}$ & & $\begin{array}{l}6.97^{* * *} \\
(2.20)\end{array}$ \\
\hline Firm & & & & & & & & \\
\hline Characteristics & Yes & Yes & No & No & Yes & Yes & No & No \\
\hline Firm FE & No & No & Yes & Yes & No & No & Yes & Yes \\
\hline
\end{tabular}

In Table 2, all of the estimates for noncognitive abilities are positive and statistically significant except for one instance. Because our composite measures for noncognitive abilities do not have numerical meanings, we discuss the estimates in terms of standard deviations. The strongest predictor of being a supervisor and the number of people supervised among the three 
noncognitive abilities is PWE. The estimates suggest that one standard deviation increase in PWE leads to an increases in the probability of being a supervisor by $2.40(0.12 \times 19.96)$ to 3.36 percentage points and an increases in the number of people supervised by $0.84-0.95$. As one third of workers hold a supervisory position and the average number of supervisees is 4.47, these estimates are equivalent to an increases in the number of people supervised by 0.84-0.95. As one third of workers hold a supervisory position and the average number of supervisees is 4.47 , these estimates are equivalent to a $7-10 \%$ increase in the probability of being a supervisor and a $19-21 \%$ increase in the number of supervisees. For workers scored one standard deviation higher in $\mathrm{C}-\mathrm{A}$, which means that they value challenge more than affiliation in a work environment, they are 1.97-2.48 percentage points (6-8\%) more likely to hold a supervisory position and supervise 0.24-0.36 (5-8\%) more employees. Workers with one standard deviation higher in LOC and thus exhibiting a stronger internal LOC are 1.53-2.14 percentage points (5-6\%) more likely to hold a supervisory position and supervise $0.47-0.70$ (11-16\%) more employees.

The two variables correlated with cognitive abilities, years of schooling and performance, are also strong predictors for holding a supervisory position and the number of people supervised. One standard deviation higher in self-report performance is associated with 6.83-7.16 percentage points (21-22\%) more likely to be a supervisor and with 1.24-1.26 (28\%) more supervisees. One additional year of schooling is associated with nearly 2 percentage points more likely to be a supervisor and with around 0.5 more supervisees; if education is also measured in standard deviations, then these estimates are equivalent to about a probability of 5 percentage points (15\%) and 1.3 more supervisees (29\%). The estimates for age and work tenure show a concave relationship similar to a standard earning regression, suggesting that the likelihood of being a supervisor and the number of supervisees increase with age and work tenure but at a decreasing rate. Also, women, especially married women, are less likely to be a supervisor and with less supervisees than men. Based on Columns (4) and (8), single women are 3.90 percentage points less likely to be a supervisor and supervise 1.11 less people compared to single men. Married women are 9.85 percentage points less likely to be a supervisor and supervise 2.87 less people compared to married men. So there is a large gender gap in supervisory status.

Table 3 presents the estimates from regressions of ever receiving promotions in the current workplace and the number of received promotions. In the left panel, Columns (1) through (4), the dependent variable is a dummy variable for ever receiving promotions, and the estimates and estimated standard errors in the left panel are scaled by 100. In the right panel, Columns (5) through (8), the dependent variable is the number of promotions received. Since promotion and supervisory status are closely related, most of the results in Table 3 are very similar to Table 2 . Both C-A and PWE are strong predictors of the likelihood of receiving promotions and the number of promotions. For workers who have preference for challenge over affiliation, the estimates suggest that one standard deviation increase in C-A leads to an increases in the likelihood of receiving at least one promotion by 1.99-3.04 percentage points (4-6\%) and an increases in the number of promotions by $0.05-0.07$ (6-8\%). For workers who adhere more to the Protestant work ethic, the estimates indicate that one standard deviation increase in PWE leads to an increase in the likelihood of receiving promotions by 1.34-1.61 percentage points (3\%) and an increase in the number of promotions by $0.06(7 \%)$. On the other hand, the estimates for LOC are small and insignificant, so LOC does not appear to be a strong predictor of 
promotion. Note that the estimates in Table 3 are potentially biased downward because we only have data on promotions received in the current workplace. Not only high ability workers may move to other firms instead of accepting promotions, but firms may recruit high ability workers from outside instead of promoting their current employees.

Table 3: Determinants of Receiving Promotions

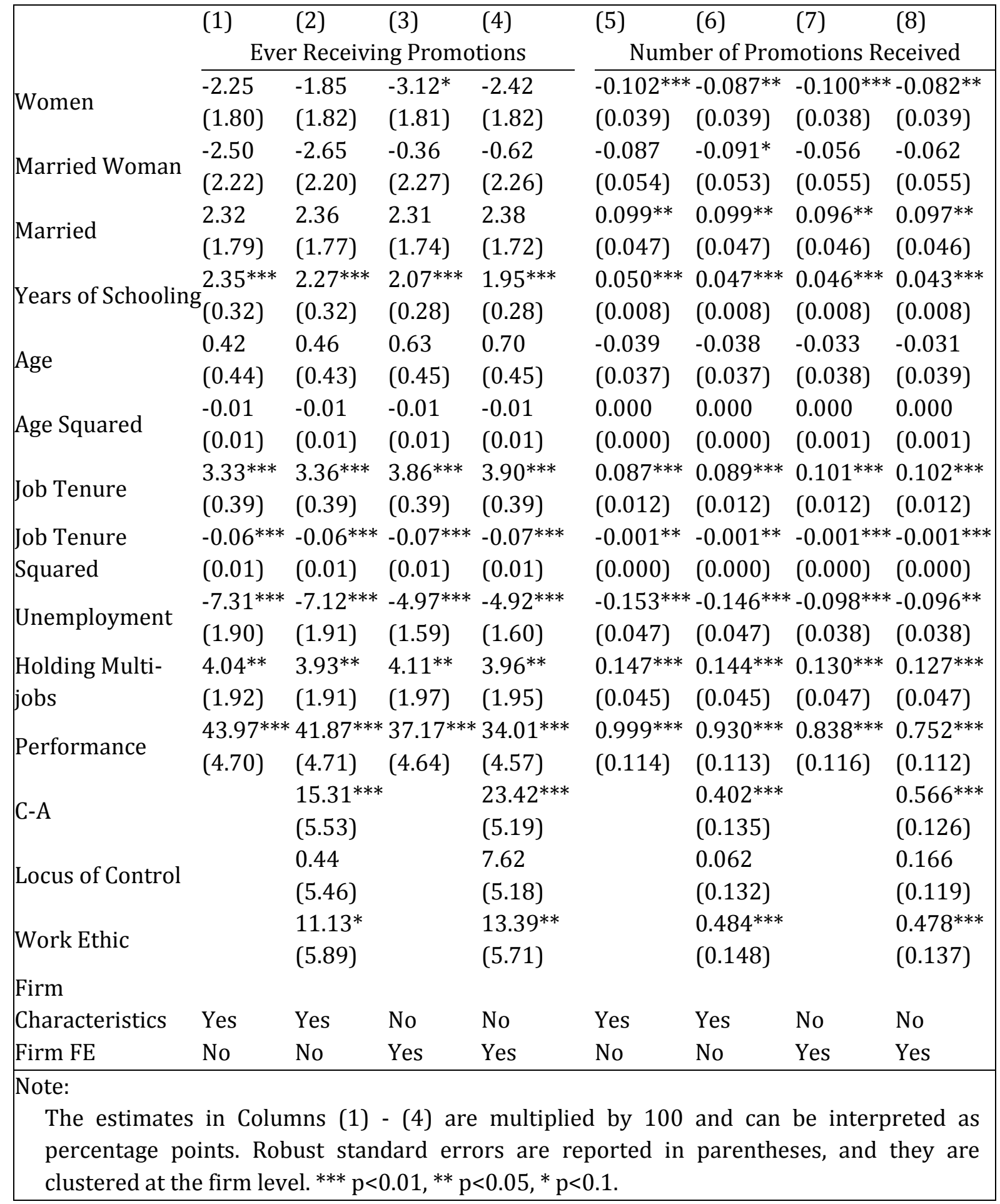

The rest of estimates in Table 3 are also very similar to those in Table 2 . The two variables that are correlated with cognitive abilities, education and performance, are strong predictors of 
receiving promotions and the number of promotions. The estimates indicate that one standard deviation higher in self-report performance is associated with 5.10-6.28 percentage points (11$13 \%)$ more likely to receive at least one promotion and with $0.11-0.14$ (12-16\%) more promotions. Also, one additional year of schooling is associated with 1.95-2.27 percentage points more likely to receive at least one promotion and with $0.43-0.47$ more promotions. In terms of standard deviations, one standard deviation higher in education is associated with a probability of 5.36-6.24 percentage points (11-13\%) more likely to receive a promotion and with 1.18-1.29 (130-143\%) more promotions. The likelihood of promotion and the number of promotion increase with work tenure at a decreasing rate. Workers holding multiple jobs are more likely to be promoted and receive more promotions. On the other hand, married women or workers with unemployment experience are less likely to be promoted and receive less promotions.

\section{Gender Gap in Supervisory Status and Promotion}

In this section, we apply the Blinder-Oaxaca decomposition to understand how gender differences in noncognitive abilities contribute to the observed gender gaps in supervisory status and promotions. It decomposes the gender gap in the outcome variable into a part that is "explained" by the mean differences of the explanatory variables and an "unexplained" part that is due to differences in coefficients. The unexplained part is often interpreted as a measure of disadvantage or discrimination against women. We focus on the extended specification with firm fixed effects that are able to nonparametrically account for firm heterogeneity. Because we are not interested in estimating these firm fixed effects but worker characteristics and noncognitive abilities, we first regress each of our dependent variables and worker-level explanatory variables on firm fixed effects, and use the residuals to perform a detailed decomposition for these worker characteristics and noncognitive abilities.

We report the decomposition of the gender gap in being a supervisor (left panel) and the number of supervisees (right panel) in Table 4. For comparison, we first present both the total decomposition with and without the noncognitive abilities, and then present the detailed decomposition for each of worker characteristics and noncognitive abilities. Column (1) in the left panel shows that the overall gender gap in holding a supervisory position is 8.69 percentage points higher for men. Column (4) in the right panel shows that the overall gender gap is 2.2 more supervisees for men. The Blinder-Oaxaca decomposition indicate that when the noncognitive abilities are included in the model the explained gender gap significantly increases and they account for a large proportion of the explained gender gap. For the explained part of the gender gap, Columns (2) and (5), all but one estimates for these noncognitive abilities are statistically significant. The gender mean-differences in C-A, LOC, and PWE together contribute to the gender gap by 0.68 percentage points and 0.173 supervisees, which are about $36 \%$ of the explained gender gap in the likelihood of being supervisor and $70 \%$ of the explained gender gap in the number of supervisees. In terms of total gender gap, about $8 \%$ of the total gender gap in being a supervisor or the number of supervisees are due to gender mean-differences in these noncognitive abilities. For the explained part of the gender gap, cognitive abilities are equally important as noncognitive abilities. The two variable that that are closely related to cognitive abilities, education and the composite measure of performance, especially education, account for a similar proportion of the explained gender gap as the noncognitive abilities. The gender mean-differences in years of schooling and performance together contribute to the gender gap 
by 0.71 percentage points and 0.162 supervisees. For the likelihood of being a supervisor, they are about $37 \%$ of the explained gender gap and $8 \%$ of the total gender gap. For the number of supervisees, they are about $66 \%$ of the explained gender gap and $7 \%$ of the total gender gap.

Most of the gender gap are from the unexplained difference in coefficients, however. Only $22 \%$ $(1.91 / 8.69)$ of the gender gap in holding a supervisory and $11 \%(0.25 / 2.20)$ of the gender gap in

Table 4: Blinder-Oaxaca Decomposition of Supervisory Status

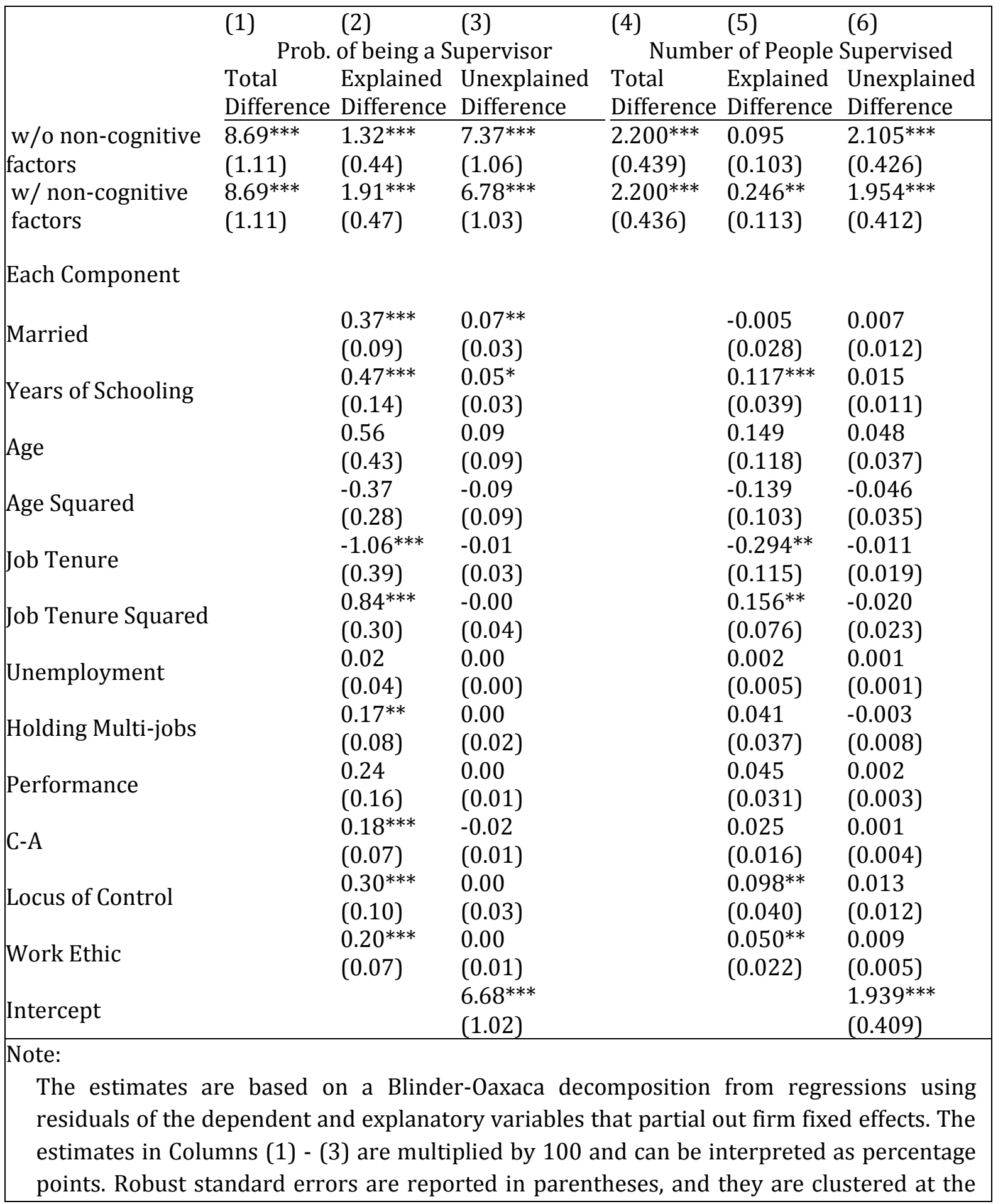


firm level. ${ }^{* * *} \mathrm{p}<0.01,{ }^{* *} \mathrm{p}<0.05,{ }^{*} \mathrm{p}<0.1$.

number of supervisees are explained by gender mean-differences in worker characteristics and noncognitive abilities. One reason for the explained gender gap to be small, especially for the number of supervisees, is that the estimates for job tenure (and its square) are negative and quite large. This is because women have almost two years longer of workplace tenure compared to men (see Table 1), and workplace tenure is a strong predictor for supervisory status. As the explained gender differences only account for $10-20 \%$ of the gender gap, the gender gap is largely driven by unobservables rather than mean-differences in explanatory variables. It suggests that women

Table 5: Blinder-Oaxaca Decomposition for Promotions

\begin{tabular}{|c|c|c|c|c|c|c|}
\hline & (1) & $(2)$ & $(3)$ & $(4)$ & $(5)$ & $(6)$ \\
\hline & \multicolumn{3}{|c|}{ Prob. of Receiving Promotions } & \multicolumn{3}{|c|}{ Number of Promotions Received } \\
\hline & Total & Explained & Unexplained & Total & Explained & Unexplained \\
\hline & Difference & Difference & Difference & Difference & Difference & Difference \\
\hline w/o non-cognitive & $2.64^{* *}$ & 0.25 & $2.39^{* *}$ & $0.093^{* * *}$ & -0.001 & $0.095^{* * *}$ \\
\hline factors & (1.14) & $(0.41)$ & (1.08) & $(0.027)$ & $(0.013)$ & $(0.025)$ \\
\hline w/ non-cognitive & $2.64^{* *}$ & 0.67 & $1.97^{*}$ & $0.093^{* * *}$ & 0.010 & $0.084 * * *$ \\
\hline factors & (1.14) & $(0.43)$ & (1.06) & $(0.027)$ & $(0.014)$ & $(0.025)$ \\
\hline \multicolumn{7}{|l|}{ Each Component } \\
\hline \multirow{3}{*}{ Married } & & $0.13^{*}$ & 0.04 & & $0.004^{*}$ & 0.001 \\
\hline & & $(0.08)$ & $(0.03)$ & & $(0.002)$ & $(0.001)$ \\
\hline & & $0.45^{* * *}$ & 0.05 & & $0.010^{* * *}$ & 0.001 \\
\hline Years of Schooling & & $(0.13)$ & $(0.03)$ & & $(0.003)$ & $(0.001)$ \\
\hline \multirow{2}{*}{ Age } & & 0.26 & 0.02 & & -0.012 & -0.004 \\
\hline & & $(0.23)$ & $(0.05)$ & & $(0.016)$ & $(0.004)$ \\
\hline \multirow{2}{*}{ Age Squared } & & -0.28 & -0.03 & & 0.015 & 0.003 \\
\hline & & $(0.24)$ & $(0.05)$ & & $(0.018)$ & $(0.004)$ \\
\hline \multirow{2}{*}{ Job Tenure } & & $-1.92^{* * *}$ & 0.02 & & $-0.050 * * *$ & 0.001 \\
\hline & & $(0.67)$ & $(0.05)$ & & $(0.018)$ & $(0.002)$ \\
\hline \multirow{2}{*}{ Job Tenure Squared } & & $1.20^{* * *}$ & -0.02 & & $0.022^{* *}$ & -0.002 \\
\hline & & $(0.41)$ & $(0.06)$ & & $(0.010)$ & $(0.002)$ \\
\hline \multirow{2}{*}{ Unemployment } & & 0.01 & -0.01 & & 0.000 & -0.000 \\
\hline & & $(0.05)$ & $(0.01)$ & & $(0.001)$ & $(0.000)$ \\
\hline \multirow{2}{*}{ Holding Multi-jobs } & & $0.17^{* *}$ & -0.01 & & $0.006^{* * *}$ & -0.000 \\
\hline & & $(0.08)$ & $(0.01)$ & & $(0.002)$ & $(0.000)$ \\
\hline \multirow{2}{*}{ Performance } & & 0.17 & 0.01 & & 0.004 & 0.000 \\
\hline & & $(0.12)$ & $(0.01)$ & & $(0.003)$ & $(0.000)$ \\
\hline \multirow{2}{*}{ C-A } & & $0.25^{* * *}$ & -0.00 & & $0.006^{* * *}$ & -0.000 \\
\hline & & $(0.08)$ & $(0.01)$ & & $(0.002)$ & $(0.000)$ \\
\hline \multirow{2}{*}{ Locus of Control } & & 0.13 & 0.03 & & 0.003 & 0.001 \\
\hline & & $(0.09)$ & $(0.03)$ & & $(0.002)$ & $(0.001)$ \\
\hline \multirow{2}{*}{ Work Ethic } & & $0.10^{* *}$ & 0.00 & & $0.003^{* *}$ & 0.000 \\
\hline & & $(0.05)$ & $(0.01)$ & & $(0.001)$ & $(0.000)$ \\
\hline \multirow{2}{*}{ Intercept } & & & $1.88^{*}$ & & & $0.082^{* * *}$ \\
\hline & & & $(1.06)$ & & & $(0.025)$ \\
\hline
\end{tabular}


The estimates are based on a Blinder-Oaxaca decomposition from regressions using residuals of the dependent and explanatory variables that partial out firm fixed effects. The estimates in Columns (1) - (3) are multiplied by 100 and can be interpreted as percentage points. Robust standard errors are reported in parentheses, and they are clustered at the firm level. ${ }^{* * *} \mathrm{p}<0.01,{ }^{* *} \mathrm{p}<0.05,{ }^{*} \mathrm{p}<0.1$.

face substantial disadvantages, or perhaps discrimination, in climbing up the ladder to management positions. Interestingly, from the detailed decomposition, the difference in intercept tem accounts for almost all of the unexplained differences in coefficients. As a result, nearly $78 \%(6.68 / 8.69)$ of the total gender gap in being a supervisor and $88 \%(1.93 / 2.20)$ of the total gender gap in the number of supervisees are not explained by any of these worker-level explanatory variables, neither their means nor their coefficients.

Table 5 presents the results of the Blinder-Oaxaca decomposition for the likelihood of receiving promotions and the number of promotions received. Column (1) in the left panel shows that the total gender gap in the likelihood of being promoted is 2.64 percentage points higher for men. Column (4) in the right panel shows that the total gender gap is 0.093 more promotions for men. The results in Table 5 are very similar to the results in Table 6; while most of the gender gap are not explained by the observed mean-difference in worker-level explanatory variables, noncognitive abilities account for a large part of explained gender gap. The gender meandifferences in C-A, LOC, and PWE together contribute to the gender gap by 0.48 percentage points and 0.012 promotions. The two proxies for cognitive abilities are also important and explain a similar size of the gender gap in promotion as these noncognitive abilities. The gender mean-differences in years of schooling and performance together contribute to the gender gap by 0.62 percentage points or 0.014 promotions. In terms of the total gender gap in promotions, about $18 \%(23 \%)$ of the total gender gap in the probability of receiving promotions and $13 \%$ $(15 \%)$ of the total gender gap in the number of promotions are due to gender mean-difference in these noncognitive (cognitive) abilities. It is somewhat difficult to interpret these estimates of explained differences in cognitive and noncognitive abilities as a proportion of the total explained gender gap, however. For the number of promotions, both the estimates for cognitive abilities and noncognitive abilities are greater than the total explained gender gap because of the large negative estimates for job tenure in Table 5. As in Table 4, it is because the estimates for job tenure are large and negative. The most important component is still the intercept term, which accounts for nearly all of the unexplained gender gap and about $72-88 \%$ of the overall gender gap in promotions.

\section{Conclusion}

This study empirically documents the effects of personality traits and work ethic on supervisory status and promotions from former socialist countries. We show that C-A, LOC, and PWE are strong predictors of the likelihood of being a supervisor or being promoted as well as the number of supervisees and promotions received. Although variables related to cognitive abilities such as education and performance are strong predictors for supervisory status, noncognitive abilities play an equally important role, and their magnitudes are about one third to one half of the magnitudes of cognitive abilities. Moreover, these noncognitive abilities can explain a modest proportion of the observed gender gaps in supervisory status and promotions. The results suggest that about $10-15 \%$ of the total gender gap can be explained by gender 
differences in $\mathrm{C}-\mathrm{A}, \mathrm{LOC}$, and PWE, which is similar to the proportion of the total gender gap that is explained by gender differences in years of education and self-report performance. On the other hand, most of the gender gap are not due to any of the explanatory variables but the unobserved gender-specific intercept term. Overall, the results suggest that noncognitive abilities are equally important factors as cognitive abilities in determining labor market outcomes.

\section{References:}

Borghans, L., Duckworth, A., Heckman, J., and Weel, B. (2008). The economics and psychology of personality traits. Journal of Human Resources, 43(4), 972-1059.

Bowles, S., Gintis, H., and Osborne, M. (2001). The determinants of earnings: a behavioral approach. Journal of Economic Literature, 39(4), 1137-1176.

Cawley, J., Heckman, J., and Vytlacil, E. (2001). Three observations on wages and measured cognitive ability. Labour Economics, 8(4), 419-442.

Costa Jr, P., Terracciano, A., and McCrae, R. (2001). Gender differences in personality traits across cultures: robust and surprising findings. Journal of Personality and Social Psychology, 81(2), 322-331.

Kosteas, V. (2011). High school clubs participation and future supervisory status. British Journal of Industrial Relations, 49, s181-s206.

Meriac, J., Poling, T., and Woehr, D. (2009). Are there gender differences in work ethic? an examination of the measurement equivalence of the multidimensional work ethic profile. Personality and Individual Differences, 47(3), 209-213.

Rothstein, D. (2001). Supervisory status and upper-level supervisory responsibilities: evidence from the NLSY79. Industrial and Labor Relations Review, 54(3), 663-680.

Schmitt, D. , Realo, A., Voracek, M., and Allik, J. (2008). Why can't a man be more like a woman? Sex differences in Big Five personality traits across 55 cultures. Journal of Personality and Social Psychology, 94(1), 168-182. 